\title{
Effect of heat treatment on structure and gasification reactivity of petroleum coke
}

\author{
Chao $\mathrm{Li}^{1} \cdot \mathrm{Xin} \mathrm{Liu}^{1,2} \cdot$ Zhijie Zhou $^{1,2} \cdot$ Zhenghua Dai $^{1,2} \cdot \mathrm{Ji}$ Yang $^{3} \cdot$ Fuchen Wang $^{1,2}$
}

Received: 8 July 2015/Revised: 31 August 2015/Accepted: 1 September 2015/Published online: 1 March 2016

(C) The Author(s) 2016. This article is published with open access at Springerlink.com

\begin{abstract}
Petroleum coke was thermally treated on a fixed bed reactor in a temperature range of 1173-1673 K. The changes of the elemental composition and crystalline structure of petroleum coke, with heat treatments as well as the gasification reactivity of the heat-treated petroleum cokes were investigated. The results showed that the petroleum coke was carbonized and graphitized to a higher degree with increasing heating temperature, while the gasification reactivity decreased. The treatment at temperatures of 1173 and $1473 \mathrm{~K}$ significantly enlarged the specific surface area and the pore volume of petroleum coke. Both the specific surface area and the pore volume decreased at $1673 \mathrm{~K}$. An empirical normal distribution function model (NDFM) was found to fit the gasification rates of petroleum coke well. The correlation coefficient of petroleum coke by normal distribution function model at different heat treatment temperatures is between 0.93 and 0.95 .
\end{abstract}

Keywords Petroleum coke $\cdot$ Heat treatment $\cdot$ Gasification reactivity $\cdot$ Graphitization

\section{Introduction}

Petroleum coke is a carbonaceous solid material produced by thermal processing of crude oil. With a continuous increase of the worldwide supply of heavy crude oil and the installation of more petroleum deep conversion processes, the output of petroleum coke is steadily increasing (Ding 2004; Zhang and Gong 2004; Zhan et al. 2010). Therefore, it has arisen as an urgent issue to dispose petroleum cokes on a large scale, especially for those with high sulfur content.

Fuchen Wang

wfch@ecust.edu.cn

1 Key Laboratory of Coal Gasification and Energy Chemical Engineering of Ministry of Education, East China University of Science and Technology, Shanghai 200237, China

2 Shanghai Engineering Research Center of Coal Gasification, East China University of Science and Technology, Shanghai 200237, China

3 School of Resources and Environmental Engineering, East China University of Science and Technology, Shanghai 200237, China
Gasification technology offers an effective way to convert petroleum coke into syngas $\left(\mathrm{CO}+\mathrm{H}_{2}\right)$ with near-zero pollutant emissions (Minchener 2005; Zheng and Furinsky 2005). It is an effective way to utilize petroleum coke to produce syngas by gasification technology. In most gasification processes, the heat treatment reaction takes place prior to the main reaction, the thermal reactions of char or coke take place as initial reactions prior to the gasification (Matsuoka et al. 2003; Ahmed and Gupta 2009; Bao 2010). It is thus necessary to study the changes in the properties of coke on heat treatments.

Some researchers reported that the char morphology and gasification kinetics of coal char are influenced by the heating rate, heating temperature and residence time (Bo et al. 2002; Cloke et al. 2002; Ichikawa et al. 2004; Miura et al. 2004). The microcrystalline structure of carbon is believed to have important effect on the gasification reactivity of char. The relationship between the char structure and the gasification reactivity has been the subject of only few researches (Barziv et al. 2000; Zaida and Sheng 2007). The purpose of this work is to investigate the changes in 
the structure and gasification reactivity of petroleum coke with high-temperature treatments.

\section{Experimental}

\subsection{Petroleum coke samples}

Two samples of petroleum coke, a Chinese petroleum coke (P1) and an America petroleum coke (P2), were supplied by Jinling Refinery Plant in Nanjing (China), and Valero Energy Corporation Refining (USA), respectively. The samples were sieved to within a size range of $83-165 \mu \mathrm{m}$. Their proximate analysis and ultimate analysis are listed in Table 1. Due to the low ash content of petroleum coke P1, it is hard to analyze the ash compositions. The ash compositions of petroleum coke P2 are listed in Table 2.

\subsection{Heat treatment}

The coke samples $(7-8 \mathrm{mg}$ ) were held in a horizontal tube furnace, alumina crucible, and then heat-treated in a horizontal tube electric furnace under a nitrogen atmosphere. The heating rate was $10 \mathrm{~K} / \mathrm{min}$. The heat treatment was kept at the final temperatures of 1223,1473 and $1673 \mathrm{~K}$ for a certain period of time $(30 \mathrm{~min})$.

\subsection{Gasification reactivity}

The measurement of the gasification reactivity of coke was carried out on a Thermo-Cahn Thermax 500 thermo gravimetric analyzer (TGA). In each experiment, a 7-8 mg sample of coke was used. A nitrogen gas of high purity (99.99\%) was purged at a flow rate of $1000 \mathrm{~mL} / \mathrm{min}$ when the sample was heated up at a heating rate of $25 \mathrm{~K} / \mathrm{min}$ until the temperature reached $1273 \mathrm{~K}$. The gasification started by switching nitrogen to carbon dioxide at the

Table 1 Properties of petroleum coke

\begin{tabular}{lrr}
\hline & P1 & \multicolumn{1}{c}{ P2 } \\
\hline Proximate analysis (air dried basis, \%) & & \\
Moisture & 1.80 & 0.30 \\
Ash & 0.26 & 3.04 \\
Volatile matter & 9.34 & 10.32 \\
Fixed carbon & 88.60 & 86.34 \\
Ultimate analysis (dry basis, \%) & & \\
Carbon & 89.15 & 85.81 \\
Hydrogen & 3.72 & 3.68 \\
Nitrogen & 0.75 & 0.35 \\
Sulphur & 2.08 & 6.10 \\
Oxygen (by difference) & 4.04 & 1.01 \\
\hline
\end{tabular}

desired temperature, and proceeded isothermally until no mass loss occurred. The mass conversion $(x)$ is calculated according to the following equation:

$x=\frac{m_{0}-m}{m_{0}-m_{\mathrm{ash}}} \times 100 \%$

where $m_{0}$ is the sample weights on a dry basis at the initial time, $\mathrm{g} ; m$ is the sample weights on a dry basis at time $t$, g; $m_{\text {ash }}$ is the weight of ash in the sample, g.

\subsection{Analysis methods}

The scanning electron microscopy (SEM) analysis was performed on a JSM-6360LV electron microscope. The specific surface area and pore volume analysis was conducted on the pore structure analyzer (ASAP 2020) using $\mathrm{N}_{2}$ adsorption. X-ray diffraction analysis was performed on a JSM-6360 LV XRD device using $\mathrm{Cu} \mathrm{K} \alpha$ radiation. The characteristic parameters $\left(d_{002}\right.$ and $\left.L_{\mathrm{c}}\right)$ of the crystalline structure of coke sample were calculated according to the following equations (Short and Walker 2003):

$d_{002}=\frac{\lambda}{2 \sin \theta_{002}}$

$L_{c}=\frac{0.94 \lambda}{\beta_{002} \cos \left(\theta_{0}\right)_{0}}$

where $d_{002}$ and $L_{\mathrm{c}}$ are, respectively, the interplanar spacing and the stacking height of the carbon crystal, $\lambda$ is the wavelength of the $\mathrm{X}$-ray radiation, $\theta_{002}$ is the position of the peak (002), and $\beta_{002}$ is the angular width at halfmaximum intensity of the peak (002).

\section{Results and discussions}

\subsection{SEM observations}

Figure 1 shows the typical SEM images of two original petroleum cokes and their samples treated at different temperatures. P1 is the most layered structure and dense in texture, somewhat regular in arrangement.

After heat-treated, P1 was more smooth, and the layered structure disappeared. In contrast, the surfaces of the original (P2) cokes were smooth and dense in texture, with a barely porous structure. However, the surfaces of the heat-treated petroleum cokes were more rough with more fold structure and some porous structure.

\subsection{Compositions of petroleum cokes}

Table 3 shows the properties of petroleum coke obtained by heat treatments. It was seen that the contents of moisture and volatile decreased with increasing heating temperature, 
Table 2 Ash compositions of petroleum coke P2

\begin{tabular}{llllllllllll}
\hline $\mathrm{SO}_{3}$ & $\mathrm{CaO}$ & $\mathrm{SiO}_{2}$ & $\mathrm{~V}_{2} \mathrm{O}_{5}$ & $\mathrm{Al}_{2} \mathrm{O}_{3}$ & $\mathrm{MgO}$ & $\mathrm{Fe}_{2} \mathrm{O}_{3}$ & $\mathrm{NiO}$ & $\mathrm{Sb}_{2} \mathrm{O}_{3}$ & $\mathrm{Na}_{2} \mathrm{O}$ & $\mathrm{K}_{2} \mathrm{O}$ & $\mathrm{TiO}_{2}$ \\
\hline 34.87 & 31.51 & 15.08 & 8.46 & 3.31 & 1.79 & 1.74 & 1.25 & 0.87 & 0.40 & 0.33 & 0.15 \\
\hline
\end{tabular}
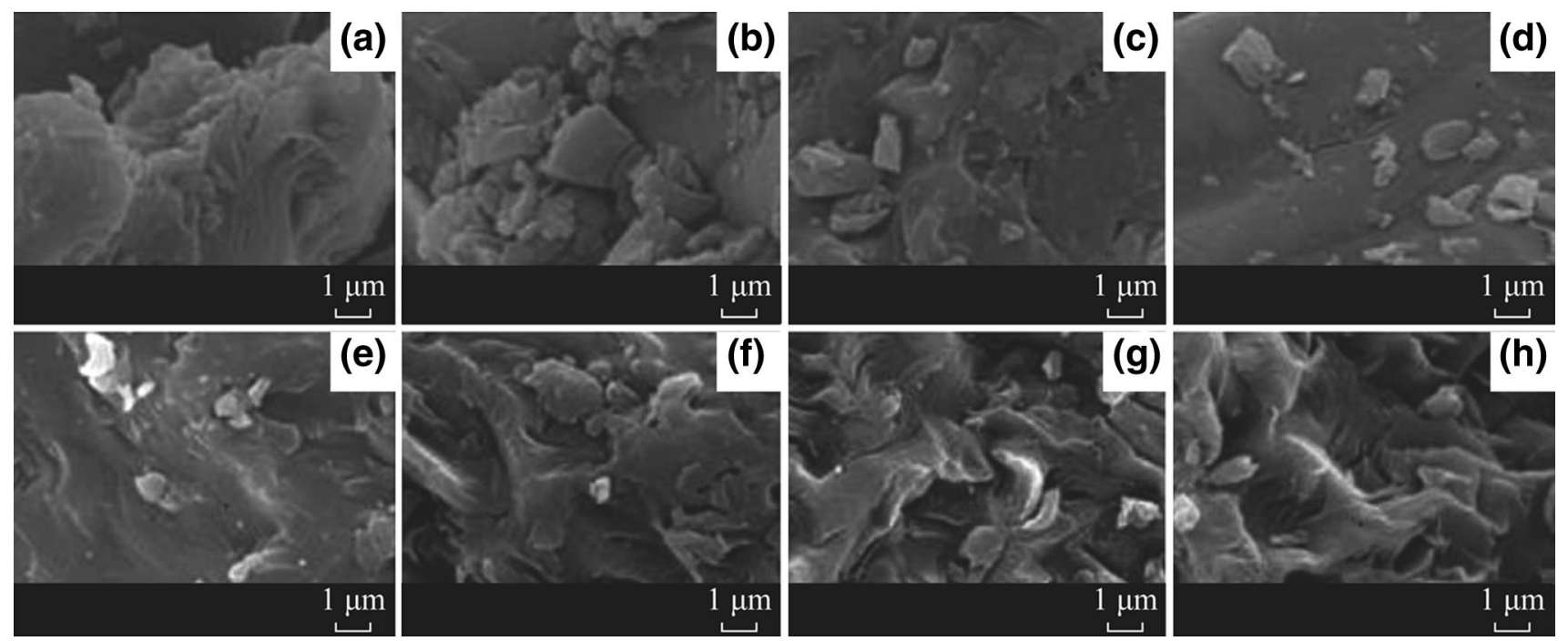

Fig. 1 SEM images of petroleum coke samples at different heat treatment temperatures. a P1, untreated; b P1, $T_{\mathrm{h}}=1173 \mathrm{~K} ; \mathbf{c} \mathrm{P} 1, T_{\mathrm{h}}=1473 \mathrm{~K}$; d P1, $T_{\mathrm{h}}=1673 \mathrm{~K}$; e P2, untreated; f P2, $T_{\mathrm{h}}=1173 \mathrm{~K} ; \mathbf{g} \mathrm{P} 2, T_{\mathrm{h}}=1473 \mathrm{~K} ; \mathbf{h} \mathrm{P} 2, T_{\mathrm{h}}=1673 \mathrm{~K}$

Table 3 Properties of petroleum coke before and after heat treatment

\begin{tabular}{|c|c|c|c|c|c|c|c|c|c|c|}
\hline \multirow[t]{2}{*}{ Sample } & \multirow[t]{2}{*}{$T_{\mathrm{h}}(\mathrm{K})$} & \multicolumn{4}{|c|}{ Proximate analysis, $w(\%)$} & \multicolumn{5}{|c|}{ Ultimate analysis, $w(\%)$} \\
\hline & & $\mathrm{M}_{\mathrm{ad}}$ & $\mathrm{A}_{\mathrm{ad}}$ & $\mathrm{V}_{\mathrm{ad}}$ & $\mathrm{FC}_{\mathrm{ad}}$ & $\mathrm{C}$ & $\mathrm{H}$ & $\mathrm{N}$ & $\mathrm{S}$ & $m(\mathrm{C}) / m(\mathrm{H})$ \\
\hline \multirow[t]{5}{*}{ P1 } & 1173 & 2.08 & 0.23 & 6.33 & 91.38 & 88.91 & 0.85 & 1.45 & 3.58 & 104.110 \\
\hline & 1323 & 0.87 & 0.24 & 3.63 & 95.27 & 91.99 & 0.85 & 1.41 & 3.76 & 107.969 \\
\hline & 1473 & 0.44 & 0.23 & 2.68 & 96.57 & 94.84 & 0.85 & 1.36 & 3.62 & 111.178 \\
\hline & 1673 & 0.16 & 0.26 & 2.00 & 97.62 & 95.87 & 0.86 & 0.78 & 3.87 & 111.471 \\
\hline & 1773 & 0.10 & 0.24 & 2.52 & 97.15 & 97.51 & 0.86 & 0.52 & 3.44 & 113.444 \\
\hline \multirow[t]{5}{*}{$\mathrm{P} 2$} & 1173 & 2.22 & 2.88 & 8.13 & 86.78 & 84.45 & 0.96 & 1.51 & 4.56 & 88.101 \\
\hline & 1323 & 2.85 & 3.11 & 7.54 & 88.10 & 83.91 & 0.93 & 1.16 & 5.63 & 90.713 \\
\hline & 1473 & 1.31 & 3.37 & 5.29 & 90.04 & 89.09 & 0.97 & 0.88 & 5.60 & 95.182 \\
\hline & 1673 & 0.27 & 4.19 & 3.83 & 91.72 & 90.48 & 0.91 & 0.52 & 6.38 & 99.872 \\
\hline & 1773 & 0.46 & 4.53 & 4.91 & 90.10 & 90.52 & 0.86 & 0.81 & 5.06 & 105.686 \\
\hline
\end{tabular}

whereas the fixed carbon increased. The molar ratio of $m(\mathrm{C}) / m(\mathrm{H})$ increased with the increasing heating temperature, implying the progressed aromaticity or carbonization of coke with preferential release of hydrogen (Xie 2002). In addition, the content of nitrogen decreased, suggesting the preferential release of nitrogen upon heat treatment.

\subsection{Graphitization of petroleum coke}

Figure 2 shows the XRD patterns of the petroleum cokes. As the heating temperature was elevated, the peak (002) reflection became sharp and gradually close to that of graphite $\left(26.6^{\circ}\right)$ in the diffraction angle (Senneca and 

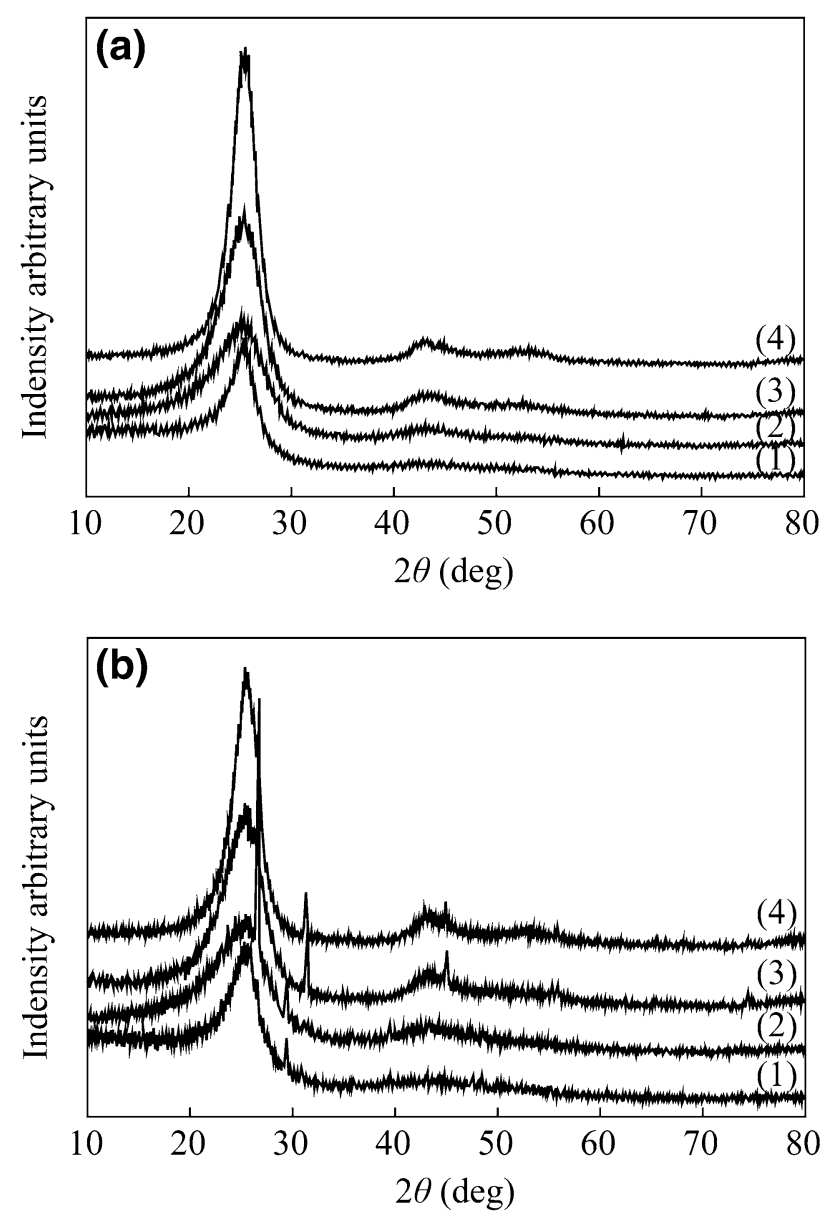

Fig. 2 XRD spectra of untreated and heat treated petroleum coke samples. a P1; b P2; (1) Untreated; (2) $T_{\mathrm{h}}=1173 \mathrm{~K}$; (3) $T_{\mathrm{h}}=1473 \mathrm{~K} ;(4) T_{\mathrm{h}}=1673 \mathrm{~K}$

Salatino 2002). In addition, the peak of (100) reflection appeared for the petroleum coke experienced by heat treatment at a temperature above $1273 \mathrm{~K}$. It was indicated that the petroleum coke trended to be graphitized to a higher degree with the heating temperature increasing.

To further quantitatively determine the degree of graphitization of petroleum cokes, the diffraction peak (002) was deconvoluted to a broad amorphous carbon (A) and turbostratic carbon ( $\mathrm{T}$ ) by a method proposed by Wang et al. (2001). In this method, it is assumed that the A and $\mathrm{T}$ carbon structures occur as a Gaussian distribution, respectively. Figure 3 shows the experiment data and the fitted data.

The scatting angles $(2 \theta)$ of peak (002) of petroleum coke samples are listed in Table 4. The calculated crystalline structure parameters of the separated carbon components are shown in Table 5, where the contents of $\mathrm{A}$ and $\mathrm{T}$, in different petroleum cokes $\left(X_{\mathrm{a}}\right.$ and $\left.X_{\mathrm{t}}\right)$ are calculated in terms of the following equations
$X_{\mathrm{a}}=\frac{S_{\mathrm{a}}}{S_{\mathrm{a}}+S_{\mathrm{t}}}, \quad X_{\mathrm{t}}=\frac{S_{\mathrm{t}}}{S_{\mathrm{a}}+S_{\mathrm{t}}}$

where $S_{\mathrm{a}}$ and $S_{\mathrm{t}}$ are the peak area of (002) peak of amorphous carbon and turbostratic carbon, and $X_{\mathrm{a}}$ and $X_{\mathrm{t}}$ are the ratio of peak area of peak (002) of amorphous carbon and turbostratic carbon. The average microcrystalline structure parameters of petroleum cokes $\left(d_{002}\right.$ and $\left.L_{\mathrm{c}}\right)$ were obtained from the following equations:

$d_{002}=X_{\mathrm{a}} d_{002, \mathrm{a}}+X_{\mathrm{t}} d_{002, \mathrm{t}}$

$L_{\mathrm{c}}=X_{\mathrm{a}} L_{\mathrm{c}, \mathrm{a}}+X_{\mathrm{t}} L_{\mathrm{c}, \mathrm{t}}$

Table 5 shows that heat treatment enables more amorphous carbon to be converted to turbotratic components, with the average interplanar spacing decreasing and the average stacking height of crystal increasing. It was evident that the polycondensation of petroleum coke was progressed with the temperature increasing, gradually forming compact and graphite-like carbon structure. It was reported that the petroleum coke was thoroughly converted to graphite at a much higher temperature of $2273 \mathrm{~K}$ (Sun and Shen 2004).

\subsection{BET surface areas and pore volumes of petroleum cokes}

Table 6 shows the BET surface areas and pore volumes of the petroleum cokes obtained at different heating temperatures. Both original petroleum cokes had lower specific surface areas and pore volumes. This result was consistent with the SEM observations. The treatment at temperatures of 1173 and $1473 \mathrm{~K}$ significantly enlarged the specific surface area and the pore volume of petroleum coke. The formation of micropore upon heat treatment was probably due to the escape of volatile matter. However, both the specific surface area and the pore volume decreased at $1673 \mathrm{~K}$, probably because the ash in the petroleum coke was melt at this high temperature and the melt blocked the micropore. The polycondensation of petroleum coke induced the structure compact, resulting in volumetric shrinkage and crack emerged. The higher the heat treatment temperature, the more fierceness the polycondensation, leading to the increased pore volume and total surface area. But when the heat treatment temperature reached $1673 \mathrm{~K}$, exceeding the ash fusion temperature of petroleum coke, the ash melting of petroleum coke resulted in that the part of pores were blocked, thereby further reduced the surface area and pore volume.

\subsection{Gasification reactivity of petroleum cokes}

Figure 4 shows the mass conversions of the petroleum cokes versus gasification time. It shows that the gasification 

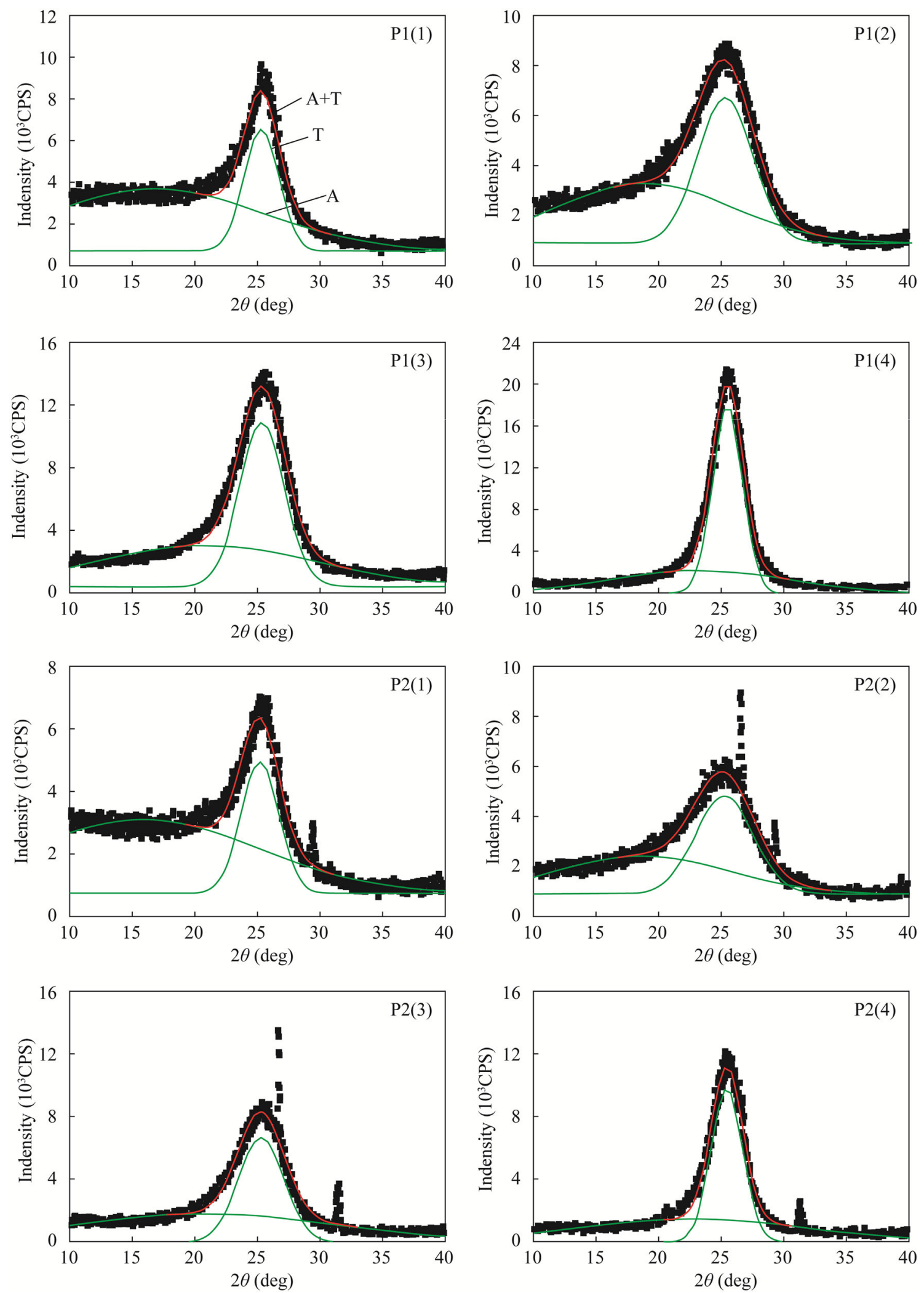

Fig. 3 Gauss fitting curves for 002 peak of petroleum coke samples. (1) Untreated; (2) $T_{\mathrm{h}}=1173 \mathrm{~K}$; (3) $T_{\mathrm{h}}=1473 \mathrm{~K}$; (4) $T_{\mathrm{h}}=1673 \mathrm{~K}$ 


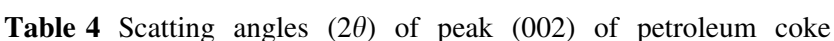
samples

\begin{tabular}{lll}
\hline Sample & $T_{\mathrm{h}}(\mathrm{K})$ & $2 \theta\left(^{\circ}\right)$ \\
\hline P1 & Untreated & 25.32 \\
& 1173 & 25.22 \\
& 1473 & 25.40 \\
& 1673 & 25.50 \\
& & \\
P2 & Untreated & 25.22 \\
& 1173 & 25.28 \\
& 1473 & 25.30 \\
& 1673 & 25.36 \\
\hline
\end{tabular}

reactivity monotonously decreased with temperature increasing for P1. Heat treatment restrained the gasification reactivity of $\mathrm{P} 1$. The $\mathrm{P} 2$ sample treated at $1673 \mathrm{~K}$ had lower gasification reactivity than the original sample, although the samples treated at lower temperature had higher gasification reactivity than the original sample. The difference between $\mathrm{P} 1$ and $\mathrm{P} 2$ was probably ascribed to the different ash contents in the two cokes. $\mathrm{P} 2$ contained more ash than P1. Alkali metals ( $\mathrm{Na}, \mathrm{K})$ and alkaline earth metals $(\mathrm{Ca}, \mathrm{Mg})$ as well as transition metals $(\mathrm{Fe})$ in $\mathrm{P} 2$ could serve as active catalysts in gasification under certain conditions. In addition, from the Table 2, we could see there is vanadium in the ash of P2, which has catalytic action (Yang et al. 2008). When the heat treatment temperature exceeded $1300 \mathrm{~K}$, some alkali metals tended to be vaporized at higher temperatures and Vanadium oxide may transformed to vanadium nitride (Yu et al. 2008), which might lead to gasification reactivity decreased.

The graphitization was the dominant factor that determined the reactivity of $\mathrm{P} 1$ coke during heat treatment process. And for the P2 coke, the effects of ash compositions and porous structure on gasification reactivity should be taken into account.

Reactivity index $R$ is one of important indicators to characterize the gasification reactivity of carbonaceous
Table 6 BET surface area and pore volume of petroleum coke

\begin{tabular}{llrl}
\hline Sample & $T_{\mathrm{h}}(\mathrm{K})$ & $S_{\text {BET }}\left(\mathrm{m}^{2} / \mathrm{g}\right)$ & $V_{\mathrm{p}}\left(\mathrm{cm}^{2} / \mathrm{g}\right)$ \\
\hline P1 & Untreated & 1.1824 & 0.00595 \\
& 1173 & 15.6229 & 0.01346 \\
& 1473 & 28.5293 & 0.01782 \\
& 1673 & 3.0254 & 0.00851 \\
& & & \\
P2 & Untreated & 1.9261 & 0.00443 \\
& 1173 & 11.0113 & 0.01604 \\
& 1473 & 35.1096 & 0.03336 \\
& 1673 & 7.2068 & 0.01950 \\
\hline
\end{tabular}

materials. The reactivity $R$ over the first $50 \%$ burnoff was reported for different heat treatment conditions, which could be seen from the Formula (7):

$R=0.5 / \tau_{0.5}$

where $\tau_{0.5}$ is the time required to reach 0.5 of fractional fixed-carbon conversion. Table 7 lists the reactivity index $R$ of petroleum coke at various reactivity temperatures before and after heat treatment, from which we could see that gasification reactivity was affected by the heat treatment temperature. The reason was that emission of the volatile content in the residual carbon during heat treatment process leads to a deeper lever graphitization of petroleum coke.

Petroleum coke is composed of polycyclic aromatic hydrocarbons and rich in aromatics with lots of rings (Bayram et al. 1999). So the carbon structure of petroleum coke is aromatic condensate, with relative higher order. Compared with other carbon materials, it has high degree of order and crystallinity. In essence, the petroleum coke is part of the graphite. When the temperature is higher than $1073 \mathrm{~K}$, the petroleum coke tends to be graphite. During the heat treatment process, the higher the temperature is, the more conducive to polycondensation reactions between hydrocarbon side chains. Thereby, the higher the degree of graphitization and microcrystalline, the more ordered of the carbon structure. In addition, the pore structure affects

Table 5 Crystal structure parameters of the petroleum coke obtained at different heating temperatures

\begin{tabular}{llllllllll}
\hline Samples & $T_{\mathrm{h}}(\mathrm{K})$ & $d_{002, \mathrm{a}}(\AA)$ & $L_{\mathrm{c}, \mathrm{a}}(\AA)$ & $d_{002, \mathrm{t}}(\AA)$ & $L_{\mathrm{c}, \mathrm{t}}(\AA)$ & $X_{a}$ & $X_{t}$ & $d_{002, \mathrm{a}}(\AA)$ & $L_{\mathrm{c}, \mathrm{a}}(\AA)$ \\
\hline P1 & Untreated & 2.66 & 0.09 & 1.80 & 0.58 & 0.76 & 0.24 & 2.45 \\
& 1173 & 2.39 & 0.11 & 1.80 & 0.36 & 0.56 & 0.44 & 2.13 & 0.21 \\
& 1473 & 2.16 & 0.09 & 1.80 & 0.44 & 0.55 & 0.45 & 2.00 \\
& 1673 & 1.95 & 0.11 & 1.79 & 0.66 & 0.42 & 0.58 & 1.86 & 0.22 \\
P2 & & & & & & & \\
& Untreated & 2.82 & 0.08 & 1.81 & 0.53 & 0.77 & 0.23 & 2.59 \\
& 1173 & 2.40 & 0.11 & 1.81 & 0.34 & 0.53 & 0.47 & 2.12 \\
& 1473 & 2.17 & 0.07 & 1.81 & 0.44 & 0.61 & 0.39 & 2.35 & 0.18 \\
& 1673 & 1.99 & 0.08 & 1.79 & 0.64 & 0.52 & 0.48 & 1.89 & 0.21 \\
\hline
\end{tabular}



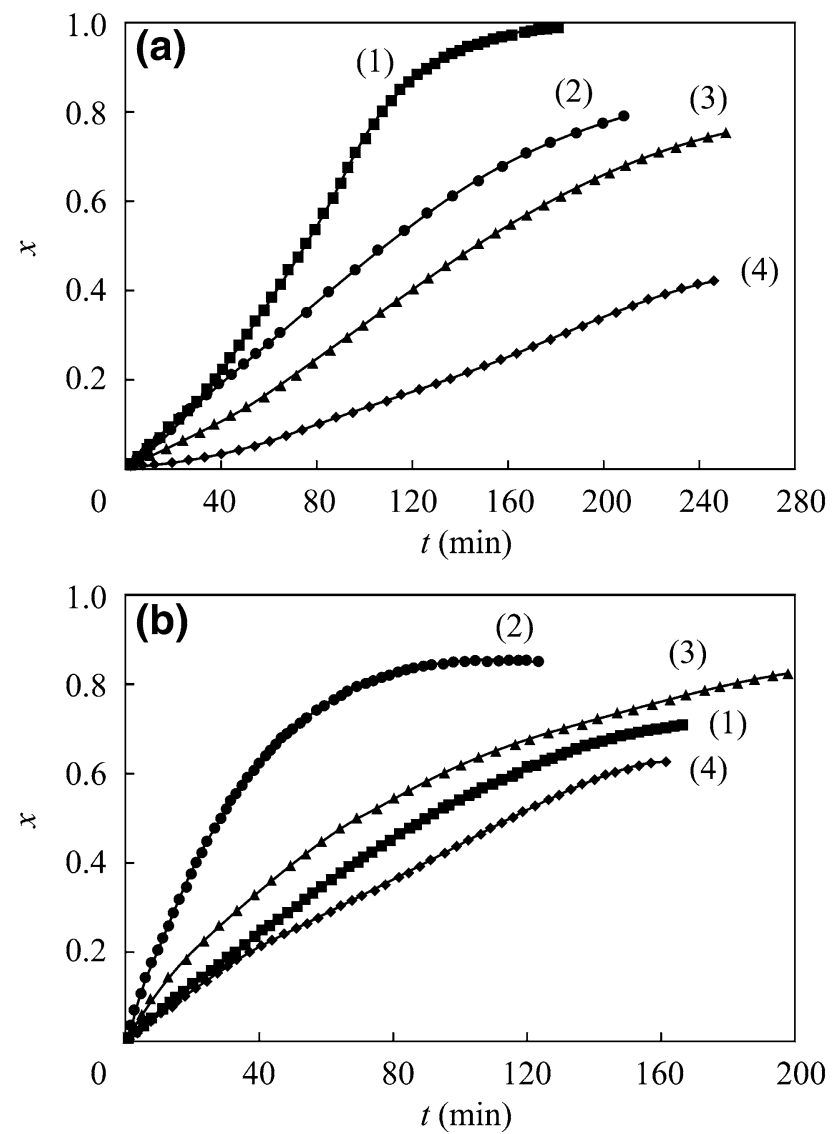

Fig. 4 Conversion rate $(x)$ plotted against gasification time $(t)$ at different heat treatment temperature. a P1; b P2; (1) Untreated; (2) $T_{\mathrm{h}}=1173 \mathrm{~K} ;(3) T_{\mathrm{h}}=1473 \mathrm{~K} ;(4), T_{\mathrm{h}}=1673 \mathrm{~K}$

Table 7 Reaction indexes $(R)$ of petroleum coke at different heat treatment temperatures

\begin{tabular}{lllll}
\hline Sample & \multicolumn{4}{l}{$R\left(\times 10^{-3} \mathrm{~min}^{-1}\right)$} \\
\cline { 2 - 5 } & Untreated & $T_{\mathrm{h}}=1173 \mathrm{~K}$ & $T_{\mathrm{h}}=1473 \mathrm{~K}$ & $T_{\mathrm{h}}=1673 \mathrm{~K}$ \\
\hline P1 & 13.472 & 9.398 & 7.285 & 2.905 \\
P2 & 11.193 & 34.540 & 14.425 & 8.648 \\
\hline
\end{tabular}

the gasification reactivity of petroleum coke. The smaller the specific surface area is, the worse the reaction is (Emmerich 1995).

As a result of the above results, carbon microcrystalline structure was the main factor of the gasification reactivity of $\mathrm{P} 1$, but the pore structure was the main factor of the gasification reactivity of $\mathrm{P} 2$. On the whole, high temperature heat treatment inhibited the gasification reactivity of petroleum coke. With the heat treatment temperature increasing, the gasification reactivity of the residual of petroleum coke decreased. The impact of heat treatment temperature on the gasification reactivity was complex. It is necessary to take all factors into consideration, including the carbon microcrystalline structure, the pore structure and its own nature of petroleum coke.

\subsection{Kinetics modeling of petroleum coke gasification}

\subsubsection{Description of kinetic models}

Various models including integrated model (IM), random pore model (RPM), and shrinking core model (SCM) have been proposed to describe coal char gasification.

IM is an improved version of shrinking core model (Yang et al. 2003). It replaces the exponent in shrinking core model by a new parameter $n$.

$r=\frac{\mathrm{d} x}{\mathrm{~d} t}=k(1-x)^{n}$

where $k$ is the reaction rate constant, and $n$ is the reaction order.

In SCM (Kajitani et al. 2002), the gasification reaction was assumed to happen only on the surface of spherical particle, and the non-reacted core shrunk gradually during the process of reaction. When reaction is the control step, the SCM gives

$r=\frac{\mathrm{d} x}{\mathrm{~d} t}=3 \tau(1-x)^{2 / 3}$

where $1 / \tau$ is particle consuming time. SCM does not take into account the evolution of pore structure in the course of reaction.

Bhatia and Perlmutter (1980) proposed RPM, which takes into account the evolution of pore in the course of reaction. A random overlapping of pore's surface was assumed to reduce the area available for reaction. When reaction is in control step, the gasification rate can be written as

$r=\frac{\mathrm{d} x}{\mathrm{~d} t}=r_{0}(1-x) \sqrt{1-\psi \ln (1-x)}$

where $\psi$ is a parameter of particle structure and $r_{0}$ is the initial reaction rate.

Normal distribution function model (NDFM) was developed by Zou et al. (2007). The gasification rate could be given by an empirical equation as

$r=\frac{\mathrm{d} x}{\mathrm{~d} t}=r_{m} \exp \left(-\frac{\left(x-x_{m}\right)^{2}}{2 w^{2}}\right)$

where $r_{\mathrm{m}}$ is the maximum reaction rate, which is determined as the maximum value of $\mathrm{d} x / \mathrm{d} t$ and can be derived from the curve of $x$ versus $t . x_{\mathrm{m}}$ is the conversion at the maximum reaction rate. 


\subsubsection{Model fitting}

IM, SCM, RPM and NDFM, were tried to fit the kinetic data of petroleum coke gasification with $\mathrm{CO}_{2}$. For petroleum coke which is poor with pore structure, the obvious graphitization is that the gasification rate decreases rapidly in the later stage of petroleum coke gasification. So typical kinetic models without consideration of the microcrystal structure cannot give good performance in describing the variation of gasification rate with conversion for petroleum coke. But from Fig. 5 and Table 8, we could see the IM and SCM cannot describe the gasification rate with conversion for petroleum coke well, which have poor correlation. Although RPM has some improvements, the correlation is still very low, and has some overlap with IM. The empirical model NDFM can describe well the variation of gasification rate with conversion for petroleum coke. The correlation factor $R^{2}$ of NDFM is more than 0.97 .

The experimental curves of the gasification rate versus conversion and the fitted data using NDFM for the heattreated petroleum cokes are shown in Fig. 6. It could be seen that the experimental data were fitted well. With the
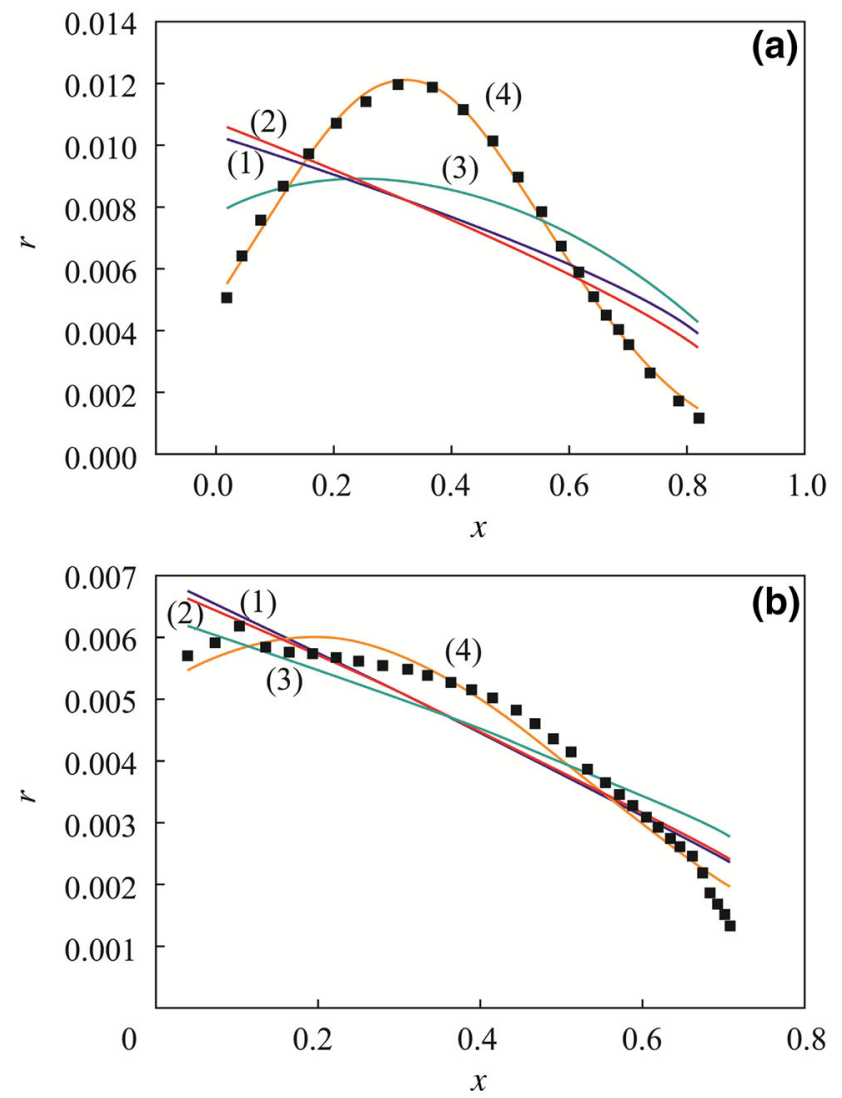

Fig. $5 r$ - $x$ curves fitted by different models: a P1; b P2; (1) IM; (2) SCM; (3) RPM; (4) NDFM
Table 8 The correlation coefficient of kinetic models

\begin{tabular}{lllll}
\hline Sample & \multicolumn{4}{l}{ Correlation coefficient $\left(R^{2}\right)$} \\
\cline { 2 - 5 } & IM & SCM & RPM & NDFM \\
\hline P1 & 0.42821 & 0.41764 & 0.58145 & 0.99691 \\
P2 & 0.89036 & 0.8444 & 0.89431 & 0.97244 \\
\hline
\end{tabular}
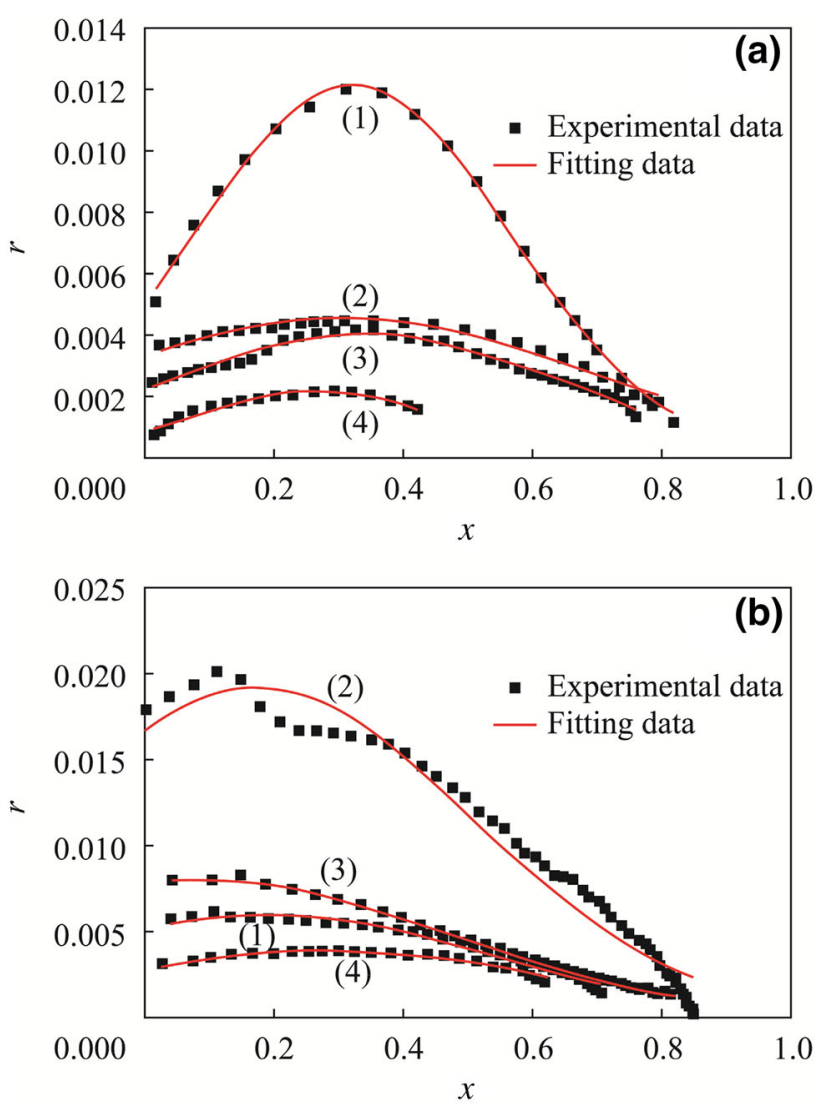

Fig. $6 r-x$ curves fitted by NDFM at different heating temperatures. a P1; b P2; (1) Untreated; (2) $T_{\mathrm{h}}=1173 \mathrm{~K}$; (3) $T_{\mathrm{h}}=1473 \mathrm{~K}$; (4), $T_{\mathrm{h}}=1673 \mathrm{~K}$

Table 9 The correlation coefficient of sample by NDFM at different heat treatment temperatures

\begin{tabular}{lllll}
\hline Sample & \multicolumn{4}{l}{ Correlation coefficient $\left(R^{2}\right)$} \\
\cline { 2 - 5 } & Untreated & $T_{\mathrm{h}}=1173 \mathrm{~K}$ & $T_{\mathrm{h}}=1473 \mathrm{~K}$ & $T_{\mathrm{h}}=1673 \mathrm{~K}$ \\
\hline P1 & 0.99691 & 0.97303 & 0.97706 & 0.95386 \\
P2 & 0.97244 & 0.96002 & 0.99884 & 0.93713 \\
\hline
\end{tabular}

correlation coefficient $\left(R^{2}\right)$ of larger than 0.93 from Table 9, NDFM is the most suitable kinetic model for the gasification of petroleum coke. 


\section{Conclusions}

(1) The petroleum coke upon heat treatment has some small scale irregular folds in the surface, with a little disorganized surface, there has yet occurred evident micropore structure. With a rise of the heat treatment temperature, the specific surface area, pore volume and $m(\mathrm{C}) / m(\mathrm{H})$ of petroleum coke are significantly increased, which suggests that carbon aromaticity index increased, the degree of graphitization became higher and the microcrystal structure turned regular with the heating temperature increasing.

(2) Heat treatment restrained the gasification reactivity of P1, but enhances the gasification reactivity of $\mathrm{P} 2$, whose gasification reactivity was gradually declining with a rise of heat treatment temperature. The difference of $\mathrm{P} 1$ and $\mathrm{P} 2$ was the P2 bore $3.04 \%$ ash, which contains catalytic alkali metals $(\mathrm{Na}, \mathrm{K})$ and alkaline earth metals $(\mathrm{Ca}, \mathrm{Mg})$ and some transition metal $(\mathrm{Fe})$. These catalytic elements would promote the gasification of $\mathrm{P} 2$.

(3) The empirical model NDFM could be regarded as the most kinetic model for the gasification of petroleum coke. The correlation coefficient of petroleum coke by NDFM at different heat treatment temperatures was more than 0.93 .

Acknowledgments The research is supported by National Key State Basic Research Development Program of China (973 Program, 2010 CB 227000), Program for Changjiang Scholars and Innovative Research Team in University (PCSIRT-IRT 0620), Shanghai outstanding academic leaders Subsidy Scheme(08 XD 1401300). Special thank is due to Professor Jie Wang for his revision of this paper.

Open Access This article is distributed under the terms of the Creative Commons Attribution 4.0 International License (http://crea tivecommons.org/licenses/by/4.0/), which permits unrestricted use, distribution, and reproduction in any medium, provided you give appropriate credit to the original author(s) and the source, provide a link to the Creative Commons license, and indicate if changes were made.

\section{References}

Ahmed I, Gupta AK (2009) Characteristics of cardboard and paper gasification with $\mathrm{CO}_{2}$. Appl Energy 88(12):2626-2634

Bao GZ (2010) Physical properties of coal and coal characteristics in the Jixi Basin Yong'an area. Appl Energy 4:16-17

Barziv E, Zaida A, Seneca O (2000) Diagnostics of carbon gasification by Raman microprobe spectroscopy. Proc Combust Inst 28:2369-2374

Bayram A, Muezzinoglu A, Seyfioglu R (1999) Presence and control of polycyclic aromatic hydrocarbons in petroleum coke drying and calcinations plants. Fuel Process Technol 60(2):111-118
Bhatia SK, Perlmutter DD (1980) A random pore model for fluidsolid reactions. I. Isothermal, kinetic control. AIChE J 26(3):335-3379

Bo F, Bhatia SK, Barry JC (2002) Structural ordering of coal char during heat treatment and its impaction reactivity. Carbon 40:481-496

Cloke M, Lester E, Belghazi A (2002) Characterization of the properties of size fractions from ten world coals and their chars produced in a drop-tube furnace. Fuel 81:699-708

Ding SR (2004) Research on the utilization of petroleum coke. Lubes Fuels 14(71):26-29

Emmerich FG (1995) Evolution with heat treatment of crystallinity in carbons. Carbon 33(12):1709-1715

Ichikawa K, Kajitani S, Oki Y, Inumaru J (2004) Study on char deposition characteristics on the heat exchanger tube in a coal gasifier-relationship between char formation and deposition characteristics. Fuel 83:1009-1017

Kajitani S, Hara S, Matsuda H (2002) Gasification rate analysis of coal char with a pressurized drop tube furnace. Fuel 81(5):539-546

Matsuoka K, Ma ZX, Akiho H, Zhang ZG, Tomita Akira (2003) High-pressure coal pyrolysis in a drop tube furnace. Energy Fuels 17:984-990

Minchener AJ (2005) Coal gasification for advanced power generation. Fuel 84(17):2222-2235

Miura K, Nakagawa H, Nakai S, Kajitani S (2004) Analysis of gasification reaction of coke formed using a miniature tubingbomb reactor and a pressurized drop tube furnace at high pressure and high temperature. Chem Eng Sci 59:5261-5268

Senneca O, Salatino P (2002) Loss of gasification reactivity toward $\mathrm{O}_{2}$ and $\mathrm{CO}_{2}$ upon heat treatment of carbons. Proc Combust Inst 29:485-493

Short MA, Walker PL (2003) Measurement of interlayer spacings and crystal sizes in turbostratic carbons. Carbon 1:3-9

Sun L, Shen BX (2004) Microcrystallite structural changes of petroleum coke during the course of carbonization analyzed by X-ray diffraction. Acta Pet Sin (Pet Process Sect) 20(2):53-56

Wang J, Morishita K, Takarada T (2001) High-temperature interactions between coal char and mixtures of calcium oxide, quartz and kaolinite. Energy Fuels 15(5):1145-1152

Xie KC (2002) The structure and reactivity of coal, 3rd edn. Science Press, Beijing, pp 94-99

Yang XF, Zhou J, Gong X (2003) Kinetic and characteristic study of char- $\mathrm{H}_{2} \mathrm{O}$ gasification by isothermal thermogravimetry. Coal Conv 26(4):46-50

Yang SL, Peng FC, Pan FS, Gao SZ (2008) Research status and application of vanadium catalyst. Mater Rev 22(4):53-56

Yu SS, Fu NX, Gao F, Sui ZT (2008) Chemical kinetics of synthesizing vanadium carbonitride by one step method. Chin J Rare Met 32(1):84-87

Zaida V, Sheng CD (2007) Char structure characterized by Raman spectroscopy and its correlations with combustion reactivity. Fuel 86:2316-2324

Zhan XL, Zhou ZJ, Wang FC (2010) Catalytic effect of black liquor on the gasification reactivity of petroleum coke. Appl Energy 87(5):1710-1715

Zhang P, Gong XS (2004) Problems investigation of petroleum coke water slurry and circulating fluidized bed boiler industrial application. Clean Coal Technol 10(2):16-21

Zheng LG, Furinsky E (2005) Comparison of Shell, Texaco, BGL and KRW gasifers as part of IGCC plant computer simulations. Energy Conver Manag 46:1767-1779

Zou JH, Zhou ZJ, Wang FC, Zhang W, Dai ZH, Liu HF et al (2007) Modeling reaction kinetics of petroleum coke gasification with $\mathrm{CO}_{2}$. Chem Eng Process 46(7):630-636 